\title{
PARÂMETROS CURRICULARES NACIONAIS OU O CURRÍCULO OFICIAL?
}

\author{
Marilde Queiroz Guedes*
}

\section{RESUMO}

Este texto objetiva compreender como foram concebidos os Parâmetros Curriculares Nacionais e qual a concepção de currículo, transversalidade e pluralidade cultural defendida por esse novo modelo curricular.

Palavras-chave: parâmetros curriculares nacionais, transversalidade, currículo, pluralidade cultural.

\section{INTRODUÇÃO}

A discussão sobre a qualidade do ensino tem conquistado espaços e tempo numa grande proporção. A escola assiste ao reforço de seu papel como espaço de construção de uma qualidade melhor de vida e convívio social. De 1996 para cá, além da qualidade do ensino, discute-se também o currículo nacional - currículo único -, que na visão do Ministério da Educação (MEC) garantirá a qualidade tão desejada e propagada.

Os Parâmetros Curriculares Nacionais (PCNs), compreendidos como currículo nacional, compõem-se das disciplinas convencionais do currículo, Português, Matemática, História, Geografia, Ciências, Artes e Educação Física, e dos temas transversais.

\footnotetext{
* Professora assistente do Departamento de Ciências Humanas da Universidade do Estado da Bahia (UNEB) e da Faculdade São Francisco de Barreiras (FASB); mestre em educação pela Faculdade de Educação da Universidade Federal de Goiás. Email:marildesguedes@bol.com.br
} 
Os temas transversais, sob a denominação "convívio social e ética", abrangem as temáticas ética, pluralidade cultural, meio ambiente, saúde, orientação sexual, trabalho e consumo.

Segundo Araújo (1996), a idéia de se incluir na estrutura curricular nas escolas do ensino fundamental e médio o que se vem chamando de temas transversais chega ao Brasil por meio da obra Los temas transversales: claves de la formacion integral.

Nessa obra, Busquets (1993) mostra que a atual estrutura curricular das escolas, que enfoca o ensino das disciplinas convencionais (Português, Matemática, História etc), tem sua origem nos núcleos de interesses intelectuais que preocupavam os pensadores da Grécia clássica há milhares de anos.

Esse modelo educacional herdado da cultura grega contribuiu para o grande desenvolvimento intelectual e tecnológico e para a compreensão do universo, da natureza e da máquina do corpo humano, mas em aspectos como a ética e a moral não houve um desenvolvimento que garantisse ao homem saber lidar com essas conquistas de maneira equilibrada em benefício da preservação da natureza e do próprio ser humano.

Segundo a autora, a proposta dos temas transversais surge na estruturação do sistema escolar espanhol com o objetivo de tentar diminuir o fosso existente entre o desenvolvimento tecnológico e a cidadania.

Por sua parte, Moreno, apud Busquets (1998, p. 29), afirma que, para os temas transversais cumprirem seus objetivos, é necessário uma mudança no eixo vertebrador dos conteúdos escolares. Ou seja, em vez de ser encarados como "fim" na educação, é preciso que esses conteúdos passem a ser "meios" para a construção da cidadania e de uma sociedade mais justa.

De acordo com o MEC, a proposta curricular brasileira tomou como eixo norteador dos temas transversais a construção da cidadania e a democracia, definindo como sua finalidade última "que alunos possam desenvolver a capacidade de posicionar-se diante das questões que interferem na vida coletiva, superar a indiferença e intervir de forma responsável" (Brasil, 1998, p. 26). Os temas transversais, 
conforme a proposta, serão integrados ao currículo por meio da transversalidade, integrando-se às áreas convencionais.

Assim, não se trata de que os professores das diferentes áreas devam 'parar' sua programação para trabalhar os temas, mas sim de que explicitem as relações entre ambos e as incluam como conteúdo de sua área, articulando a finalidade do estudo escolar com as questões sociais, possibilitando aos alunos o uso dos conhecimentos escolares em sua vida extra-escolar. (Brasil, 1998, p. 27)

A concepção de transversalidade explícita nos parâmetros diz respeito à possibilidade de se estabelecer, na prática educativa, uma relação entre a aprendizagem dos conhecimentos teoricamente sistematizados (aprender sobre a realidade) e a das questões da vida real e sua transformação (aprender na realidade e da realidade). A transversalidade para Gallo, apud Barreto (1996, p. 134),

aponta para o reconhecimento da pulverização da multiplicização, para o respeito às diferenças, construindo possíveis trânsitos pela multiplicidade dos saberes sem procurar integrá-los artificialmente, mas estabelecendo policompreensões infinitas.

Adentrando um pouco mais no estudo do documento, nota-se uma certa contradição no que diz respeito à exploração dos temas pelo veio da transversalidade: esses temas serão integrados às áreas convencionais, e o próprio documento afirma que não é possível fazer um trabalho pautado na transversalidade tomando-se uma perspectiva disciplinar rígida. Ao mesmo tempo, sustenta que com a inserção dos temas o currículo ganha em flexibilidade e abertura.

Para Macedo (1998) os temas transversais propostos pelo MEC apresentam-se como mais uma tentativa de articulação entre as diferentes disciplinas que compõem o currículo, tendo por justificativa a incapacidade dessas mesmas disciplinas de darem conta da realidade social. A autora levanta questionamentos quanto à relevância dessas temáticas para a formação do educando e pergunta por que não são os temas transversais os princípios estruturadores do currículo, inse- 
rindo-se as disciplinas tradicionais "transversalmente". Ou seja, Macedo propõe a inversão do princípio gerador da proposta.

Uma das questões que ora se levanta na realidade das escolas brasileiras é a forma de abordar os temas transversais no currículo vigente, que ainda tem as disciplinas tradicionais como eixos norteadores dos conteúdos escolares. Este trabalho tem como objetivo compreender como foi concebido esse novo modelo curricular e suas implicações na prática pedagógica.

\section{PROCESSO DE CONSTRUÇÃO DOS PCNs}

Inicialmente é importante lembrar que o estabelecimento dos PCNs é fruto das exigências do Plano Decenal de Educação para Todos (1993-2003), que, em consonância com a Constituição de 1988, afirma a necessidade e a obrigação de o Estado elaborar parâmetros para orientar as ações educativas. Uma das metas do Plano Decenal é

incrementar em cerca de $50 \%$ os atuais níveis de aprendizagem nas matérias do Núcleo Comum, tomando como referência os novos padrões de conteúdos mínimos nacionais e de competências básicas a serem nacionalmente determinadas com a participação dos sistemas de ensino. (Brasil, 1993, p. 42)

Segundo as primeiras informações veiculadas nos PCNs, seriam estabelecidas quatro etapas:

- Etapa de elaboração - o MEC faria uma proposta e a apresentaria em versão preliminar para uma discussão em âmbito nacional, nos anos de 1995 e 1996, com a participação dos docentes de universidades, técnicos de secretaria, instituições, especialistas etc. Infelizmente essa primeira etapa não funcionou adequadamente, uma vez que deixou à margem os verdadeiros interessados e atores do processo ensino-aprendizagem (os alunos e professores), além de não haver chegado a todas as universidades. Ficou sob a responsabilidade de um grupo restrito de especialistas e de consultores de outro país, margi- 
nalizando pesquisadores brasileiros com estudo na área de currículo.

- Etapa de divulgação - ficou a cargo do próprio MEC, que utilizou a revista Nova Escola (abril, 1995) para tornar pública a política de elaboração do Currículo Básico Nacional. Em entrevista à Nova Escola, a professora Iara Prado, secretária da Educação Fundamental do MEC, esclarece:

O currículo era um dos cinco pontos fundamentais da estratégia para o Ensino de Primeiro Grau anunciada pelo Presidente Fernando Henrique Cardoso em fevereiro de 1995; tratava-se do Currículo Básico, embora o denominasse Parâmetros Curriculares, pois a existência de parâmetros curriculares facilita a avaliação do ensino, a formação de professores em âmbito nacional e a produção de livros didáticos; é uma política de curto, médio e longo prazos que desenvolverá pelo menos quatro anos de governo, permitindo atingir nosso principal objetivo, que é a qualidade do ensino. (p. 52)

- Etapa de adaptação - de responsabilidade dos Estados, que poderão elaborar suas diretrizes.

- Etapa de adequação - essa, na visão do MEC, será de responsabilidade das escolas e dos professores, o que suscita várias indagações: por que os professores não puderam ser autores, mas são obrigados a ser executores? Qual a concepção de parâmetros para a maioria dos professores do ensino fundamental? Diante dos diversos limites das escolas e dos professores, como será implementado esse modelo de currículo? Qual o sentido de um currículo nacional? Quem sairá prejudicado? Para Apple (1994, p. 61), só faz sentido um currículo nacional se se quer privilegiar o controle do que se passa nas salas de aula e atrelar a educação à rentabilidade econômica e aos interesses do livre mercado: "por trás das justificativas educacionais para um currículo e um sistema de avaliação nacionais, está uma perigosíssima investida ideológica". 
Os estudos têm mostrado que o currículo não é um elemento inocente e neutro de transmissão desinteressada de conhecimento social. Ele está implicado em relações de poder e é resultado de uma tradição seletiva de alguém, da visão de algum grupo acerca do que seja conhecimento legítimo. De acordo com Moreira (1997), um currículo nacional privilegiará, certamente, os discursos dos dominantes, tendendo a "excluir das salas de aula os discursos e as vozes dos grupos sociais oprimidos, vistos como não merecedores de serem ouvidos no espaço escolar".

\section{REORGANIZAÇÃO DO ENSINO FUNDAMENTAL}

Com o novo modelo curricular o ensino fundamental passa a ser organizado por ciclos, estabelecendo equivalência com o modelo seriado: primeiro ciclo (primeira e segunda séries); segundo ciclo (terceira e quarta séries); terceiro ciclo (quinta e sexta séries) e quarto ciclo (sétima e oitava séries). Conforme o documento introdutório dos parâmetros, a adoção dos ciclos se deve ao reconhecimento de que tal organização permite compensar a pressão do tempo inerente à instituição escolar, tornando possível distribuir os conteúdos de forma mais adequada à natureza do processo de aprendizagem.

Confrontando a concepção de ciclos posta nos parâmetros com o pensamento de Arroyo (1999), podemos ousar dizer que aquela não passa de um mascaramento da reprovação e da irresponsabilidade para com a educação. A lógica da seriação recebeu uma nova pintura, mas não mudou sua estrutura arquitetônica. Como diz Arroyo (1999), "ciclo não é um amontoado de séries. Se assim fosse, não precisaria mudar. Ciclo é uma nova lógica, uma nova concepção de ensino - a lógica do desenvolvimento de crianças, adolescentes, jovens e adultos".

Apesar da adoção dos ciclos, foi mantida a organização disciplinar do currículo, com a inclusão dos temas transversais, o que traz a idéia de inovação curricular. As disciplinas tradicionais passam a ser chamadas de áreas: (área de Língua Portuguesa, área de Matemática etc.), e as práticas transdisciplinares - "convívio social”-, de 
temas transversais (ética, saúde, orientação sexual, meio ambiente, pluralidade cultural e trabalho e consumo).

Sobre a disciplinarização do currículo, coloca Gallo (1997, p. 115):

No ensino contemporâneo, sofremos da excessiva compartimentalização do saber. A organização como realidade estanque, sem interconexão alguma, dificultando para os alunos a compreensão do conhecimento como um todo integrado à construção de uma cosmovisão abrangente que lhes permita uma percepção totalizante da realidade.

Por se tratar de uma proposta que se diz inovadora, longe está da superação da fragmentação histórica dos saberes.

\section{PLURALIDADE CULTURAL}

A cultura escolar delimitada pelo currículo explícito e por esse currículo real que se plasma nas práticas escolares ou por aquele que vemos refletido nos materiais pedagógicos - especialmente nos livros didáticos - está longe de ser um resumo representativo de todos os aspectos, dimensões ou invariantes da cultura da sociedade na qual surge o sistema escolar. O currículo seleciona elementos, valoriza mais certos componentes em relação a outros e também oculta dos alunos certos aspectos da cultura que rodeia a escola. (J. Gimeno Sacristán, 1995)

A temática da pluralidade cultural diz respeito ao conhecimento e à valorização de características étnicas e culturais dos diferentes grupos sociais que convivem no território nacional, às desigualdades socioeconômicas e à crítica às relações sociais discriminatórias e excludentes que permeiam a sociedade brasileira. Por meio da pluralidade cultural o aluno tem a possibilidade de conhecer o Brasil como um país complexo, multifacetado e algumas vezes paradoxal (Brasil, 1998).

Neste contexto de crescente globalização a necessidade de uma educação para a diversidade cultural tem sido defendida por 
diversos autores da literatura nacional e internacional. Canen (1998) apresenta os argumentos básicos para essa defesa:

- os avanços da tecnologia, da mídia e da informática, que propiciam a diluição de fronteiras geográficas e o intercâmbio entre culturas distintas, de forma a exigir uma sensibilização para a pluralidade de valores e universos culturais cada vez mais presentes no cotidiano de educadores, alunos e profissionais;

- a filtragem de valores dominantes e de uma cultura predominantemente imbuída de valores consumistas, que põe em xeque culturas locais e estabelece um processo de homogeneização ameaçador das identidades culturais específicas;

- a exclusão social reforçada pela globalização, que não beneficia igualmente os diversos grupos socioculturais e consubstancia processos discriminatórios, de racismo e xenofobia, atingindo particularmente, grupos socioculturais fragilizados economicamente.

Esses argumentos são considerados pela autora como fundamentais para uma visualização da diversidade de discursos que se apropriou da expressão "pluralidade cultural" com pressupostos teóricos e implicações pedagógico-curriculares diferentes. Ela pontua, também, que no âmbito da educação multicultural é imprescindível uma postura intelectual crítica para o desafio a estereótipos e a construção de práticas educativas voltadas para a valorização da cidadania plural.

Nessa mesma perspectiva diz Santomé (1995, p. 179):

O discurso educacional tem que facilitar que as crianças de etnias oprimidas, assim como as dos grupos dominantes, possam compreender as inter-relações entre preconceitos, falsas expectativas e condições infra-humanas de vida das populações marginalizadas com as estruturas políticas, econômicas e culturais dessa mesma sociedade.

A temática "pluralidade cultural" sofre das mesmas limitações curriculares da proposta dos PCNs, apontadas por Moreira (1997), por não ter uma participação efetiva da comunidade acadêmica, pelo excesso de prescrições em sua estrutura e pela abordagem de veio 
exclusivamente psicológico.Sobre esse viés psicologizante, a Faculdade de Educação da Universidade Federal do Rio Grande do Sul, em maio de 1996, enviou ao MEC um documento em que fazia a seguinte avaliação dos CNs:

a única base teórica sob a qual repousa o documento introdutório é a Psicologia e a Pedagogia, sendo totalmente ignoradas as importantes e centrais contribuições da Sociologia da Educação, da Sociologia do Currículo, da Filosofia da Educação, dos Estudos Culturais e de outras áreas de pesquisa e estudo que têm examinado e analisado o currículo e a educação sob uma perspectiva mais ampla ressaltando sobretudo sua implicação em relações de poder e construção de identidades sociais.

Numa crítica mais enfática a esse viés psicologizante Santomé, apud Moreira (1997), esclarece:

É óbvio que recorrer a uma ciência com exclusividade serve, em muitas ocasiões, para disfarçar sob a capa dos raciocínios científicos o que não é outra coisa senão interesses políticos, decisões que podem beneficiar a um grande número de cidadãos e cidadãs, a coletivos sociais com interesses mais ou menos legítimos etc., porém, ao mesmo tempo, não atenuam ou não fazem suficiente empenho na defesa de grupos sociais mais desfavorecidos e marginalizados.

Diversos autores têm questionado a viabilidade de se tratar a pluralidade cultural como tema transversal, receando que a "impregnação" de tal proposta nas diferentes áreas do currículo possa ser tão tênue a ponto de se tornar invisível. Alves e Mazzotti (1994) falam da relevância de se promover a conscientização acerca da educação multicultural como necessária à promoção de cidadãos críticos e participativos em sociedades cada vez mais multiculturais. Dessa forma, a educação multicultural deveria ser enfatizada no interior de todas as áreas trabalhadas, bem como no trabalho das representações sociais de docentes, sob pena de reduzir-se a um "imperativo 
moral" consensualmente aceito no currículo formal, porém não efetivamente implementado nas práticas curriculares vivenciadas.

Considerando as limitações na formação do professor (a maioria só cursou o Magistério de Segundo Grau); as condições precárias de trabalho (falta de um planejamento participativo, horários de estudo, livros para consulta); o elenco de áreas a serem exploradas nesse campo (fundamentos éticos, jurídicos, históricos, geográficos, sociológicos, antropológicos, de linguagem, de representações populacionais, psicológicos e pedagógicos) e os objetivos do tema, há que se ter preocupação com a superficialidade em que poderão ser trabalhados todos os temas transversais, não somente a pluralidade cultural. $\mathrm{O}$ documento $(\mathrm{CN})$ até cogita a necessidade da formação do professor no tema da pluralidade cultural, mas não diz como, quando e por quem será bancada essa formação.

$\mathrm{Na}$ análise feita por Canen (1998), dos temas e subtemas elencados na proposta de trabalho com a pluralidade cultural, observou-se que as tentativas de reconhecimento da pluralidade indentitária de grupos socioculturais e a busca de superação da homogeneização cultural não parecem incluir docentes e discentes na problemática apontada. Ao contrário, trata-se de falar da pluralidade cultural em termos que a afastam das dimensões temporais e espaciais da realidade do cotidiano escolar, limitando-a a um tom narrativo referente a fatos históricos ou a ritos e costumes atinentes àqueles grupos destacados. Com isso, diz a autora,

enfatiza-se o outro, sem que se promova a conscientização da pluralidade cultural e dos estereótipos a elas relacionados no interior do próprio espaço escolar e das práticas sociais mais amplas, em uma perspectiva intercultural crítica. (Canen, 1998, p. 8)

A propósito, Santomé (1998) chama a atenção para não se cair no currículo de turistas, em que a informação sobre comunidades silenciadas, marginalizadas, oprimidas e sem poder é apresentada de maneira deformada, com grande superficialidade, centrada em episódios descontextualizados, e passa a ser contemplada de uma 
perspectiva distante, como algo que não tem a ver com cada uma das pessoas que se encontram na sala de aula.

É sabido também, e os estudos da sociologia do currículo o têm mostrado, que os estudantes não se constituem em passivos receptores de conteúdos, atitudes e hábitos, e têm-se acentuado as resistências e os conflitos envolvidos na prática pedagógica. Tais estudos examinaram como, na prática curricular, interagem elementos de classe social e de cultura, possibilitando então que se pense em uma política cultural apoiada em interesses emancipatórios.

Especialistas diversos apontam para a necessidade de considerarmos a cultura de origem e a experiência de vida do aluno como ponto de partida de uma prática pedagógica voltada para os interesses dos setores populares, tão marginalizados em suas culturas. Segundo Moreira e Silva (1994), a cultura deve ser vista como um campo de luta. Luta pela manutenção ou superação das divisões sociais. O currículo educacional é o veículo de manifestação desse conflito, o terreno em que ativamente se criará e produzirá cultura.

É fato que a escola se encontra marcada por práticas cultural e historicamente arraigadas de privilegiamento da cultura dominante. Mas, sendo o Brasil um país marcado pela diversidade cultural, é fundamental que ela tome consciência dessa realidade e repense sua prática. Conforme Gramsci (1992), a cultura deve proporcionar ao homem o conhecimento e a compreensão de seu valor histórico, de sua própria função na vida e de seus direitos e deveres. Isso só é possível pela reflexão crítica e inteligente de toda uma classe. A escola não pode fugir dessa responsabilidade perante a adversidade cultural.

De acordo com Gadotti (1996), a educação pós-moderna e multicultural defende o respeito à diversidade, às minorias étnicas, à pluralidade de doutrinas e aos direitos humanos, eliminando os estereótipos e ampliando o horizonte de conhecimentos e divisões de mundo. O plano de uma sociedade democrática implica uma proposta de pluralidade cultural na educação e nas representações sociais em geral. E, para Cunha Júnior (1998), essa proposta depende de um amplo trabalho social e prevê uma reelaboração das representações sociais dos diversos grupos ou classes na cultura nacional. 
Para concluir, citamos a Parábola do monstro do lago, a título de demonstração do risco de se correr atrás da pluralidade cultural sem considerar as múltiplas culturas do país e sem questionar a exclusão social veiculada pela educação:

Era uma vez um grupo de pessoas que queria atravessar um lago. Entravam no barco, começavam a remar, e lá aparecia um terrível monstro. Todos se empenhavam em dar cabo dele, e com isso o barco não saía do lugar, uma vez que as energias se concentravam unicamente no enfrentamento do tal monstro.

Por fim, o monstro morreu. De imediato, todos ficaram muito felizes, e alguns, parados, visto que, depois de tanto tempo lutando com o monstro, não se conformavam com seu desaparecimento. Passaram, portanto, a ocupar a maior parte do seu tempo em procurar eventuais sinais seus no lago. Outros tinham perdido a clareza do que almejavam atravessar o lago (Revista de Educação AEC, abr./ jun. 1999, p. 94).

Um currículo nacional que reduz a diversidade cultural a um conjunto de identidades "homogêneas" sem problematizar criticamente esse modelo excludente de educação poderá desviar a atenção dos mais ingênuos do principal objetivo - promover uma educação antimarginalizadora e viabilizadora da formação de cidadãos críticos e participantes em sociedades cada vez mais multiculturais. Como diz Coutinho (1997), a educação multicultural busca a formação de cidadãos multiculturalistas, não apenas de sujeitos epistêmicos. Preocupa-se em formar seres humanos inseridos no contexto histórico e dotados de liberdade, de espírito crítico e de variadas competências multiculturais (inclusive a de saber apoiar uma ou mais culturas).

No limiar do século XXI, vivendo o movimento histórico-social denominado pós-moderno por vários teóricos, é imprescindível se pensar em um currículo antimarginalização, que na concepção de Santomé (1998) é aquele que aceita, respeita e valoriza todas as culturas, na tentativa de recuperar aquelas que são negadas e silenciadas na escola - na sociedade.

Os críticos Michael Apple, Tomaz Tadeu da Silva e Antônio Flávio B. Moreira propõem como alternativa um currículo que 
parta das desigualdades e da diversidade e que garanta espaço para as diferentes vozes dos diferentes grupos [...] valorizando e incorporando no currículo as culturas vividas por nossos estudantes, respeitando suas experiências e seus saberes, assim como promovendo a crítica e o diálogo dos mesmos com outros saberes e outras experiências, desconstruindo as tradicionais fronteiras entre a cultura erudita, reconhecendo que a nossa cultura é marcadamente híbrida.

Moreira (1997) também sugere que o fortalecimento de lutas contra a hegemonia da globalização cultural e ainda a historização dos conteúdos ensinados se constituam em princípio orientador das reestruturações curriculares. Se a proposta da pluralidade cultural for trabalhada dentro dessa perspectiva poderá contribuir para a efetivação desse objetivo.

\section{ABSTRACT}

In order to discuss the Curriculum National Parameters it's necessary to comprehend the education in a large point of view. Thus, in this perspective, we must work with the PCNs in a plural cultural purpose and not as someone who affirme traditional experiences.

Keywords: curriculu parameters, cultural plurality.

\section{REFERÊNCIAS}

APPLE, Michael W. Na política do conhecimento oficial faz sentido a idéia de um currículo nacional? In: MOREIRA, Antônio Flávio Barbosa; SILVA, Tomaz Tadeu da. (Org.). Currículo, cultura e sociedade. São Paulo: Cortez, 1994.

ARROYO, Miguel G. Ruptura e continuidade na prática pedagógica. Goiânia: Faculdade de Educação da UFG, 1999. Palestra. 
ARAÚJO, Ulisses Ferreira de. Ética, moral, cidadania - a importância dos temas transversais na escola. AMAE/Educando, n. 262, 1996.

BARRETO, Ana Leda Vieira. Parâmetros curriculares nacionais para o ensino fundamental: uma reação ao Documento Introdutório. Revista de Educação AEC, Brasília, p. 131-142, abr./jun. 1996.

BRASIL. Ministério da Educação. Plano decenal de educação para todos. Brasília, 1993.

BRASIL. Ministério da Educação. Secretaria de Educação Fundamental. Parâmetros curriculares nacionais: temas transversais. Brasília, 1998.

BUSQUETS, Maria Dolors et alii. Temas transversais em educação - bases para uma formação integral. São Paulo: Ática, 1998.

CANEN, A. Educação multicultural, identidade nacional e pluralidade cultural: tensões e implicações curriculares. REUNIÃO ANUAL DA ANPED, 21., 1998.

COUTINHO, José Maria. Por uma educação multicultural: uma alternativa de cidadania para o século XXI. Revista da FAEEBA, Salvador, n. 8, jul./dez. 1997.

CUNHA JÚNIOR, Henrique. Afrodescendência, pluralismo e educação. Pátio - Revista Pedagógica, n. 6, 1998.

GADOTTI, Moacir. História das idéias pedagógicas. São Paulo: Ática, 1996.

GALLO, Sílvio. Conhecimento, transversalidade e educação: para além da interdisciplinaridade. Revista Impulso, n. 21, 1997.

MACEDO, Elisabeth Fernandes de. Parâmetros Curriculares Nacionais: a falácia dos seus temas transversais. Revista de Educação AEC, Brasília, v. 27, n. 108, jul./set. 1998.

MOREIRA, Antônio Flávio Barbosa ; SILVA, Tomaz Tadeu da. (Org.). Currículo, cultura e sociedade. São Paulo: Cortez, 1994. 
MOREIRA, Antônio Flávio Barbosa. A Psicologia e o resto: o currículo segundo César Coll. Caderno de Pesquisa, n. 100, p. 93-103, 1997.

NOSELLA, Paolo. A escola de Gramsci. Porto Alegre: Artes Médicas, 1992.

REVISTA de Educação AEC, Brasília, abr./jun. 1999.

SACRISTÁN, J. Gimeno. Currículo e diversidade cultural. In: MOREIRA, Antônio Flávio; SILVA, Tomaz Tadeu da. (Org.). Territórios contestados: o currículo e os novos mapas políticos e culturais. Petrópolis, RJ: Vozes, 1995.

SANTOMÉ, Jurjo Torres. Globalização e interdisciplinaridade: o currículo integrado. Porto Alegre: Artes Médicas, 1998.

As culturas negadas e silenciadas no currículo. In: SILVA, Tomaz Tadeu da. (Org.). Alienígenas na sala de aula. Petrópolis, RJ: Vozes, 1995. 
